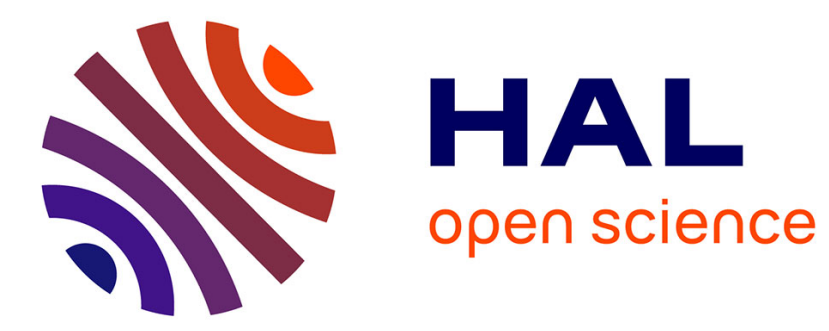

\title{
Self-erasable inkless imprinting using a dual emitting hybrid organic-inorganic material
}

S. Khlifi, N. Fournier Le Ray, Serge Paofai, M. Amela-Cortes, H. Akdas-Kiliç, G. Taupier, S. Dérien, Stéphane Cordier, M. Achard, Y. Molard

\section{- To cite this version:}

S. Khlifi, N. Fournier Le Ray, Serge Paofai, M. Amela-Cortes, H. Akdas-Kiliç, et al.. Self-erasable inkless imprinting using a dual emitting hybrid organic-inorganic material. Materials Today, 2020, 35, pp.34-41. 10.1016/j.mattod.2019.12.002 . hal-02865283

\section{HAL Id: hal-02865283}

\section{https://hal-univ-rennes1.archives-ouvertes.fr/hal-02865283}

Submitted on 19 Jun 2020

HAL is a multi-disciplinary open access archive for the deposit and dissemination of scientific research documents, whether they are published or not. The documents may come from teaching and research institutions in France or abroad, or from public or private research centers.
L'archive ouverte pluridisciplinaire HAL, est destinée au dépôt et à la diffusion de documents scientifiques de niveau recherche, publiés ou non, émanant des établissements d'enseignement et de recherche français ou étrangers, des laboratoires publics ou privés. 


\title{
Self-erasable Inkless Imprinting Using a Dual Emitting Hybrid Organic-Inorganic Material
}

\author{
Soumaya Khlifi, ${ }^{a}$ Nicolas Fournier Le Ray, ${ }^{a}$ Serge Paofai, ${ }^{a}$ Maria Amela-Cortes, ${ }^{a}$ Huriye Akdas-Kiliç, ${ }^{a}$ \\ Grégory Taupier, ${ }^{a}$ Sylvie Derien, ${ }^{a}$ Stéphane Cordier, ${ }^{a}$ Mathieu Achard, ${ }^{a}$ and Yann Molard ${ }^{* a}$
}

\author{
S. Khlifi, N. Fournier Le Ray, S. Paofai, Dr. M. Amela-Cortes, Dr. H. Akdas-Kiliç, Dr. G. Taupier, \\ Dr. Sylvie Derien, Dr. S. Cordier, Dr. M. Achard, Dr. Y. Molard \\ Univ Rennes, CNRS, ISCR - UMR 6226, ScanMAT - UMS 2001, F-35000 Rennes, France \\ E-mail : yann.molard@univ-rennes1.fr
}

\begin{abstract}
Smart emissive materials that can react to external stimuli in a reversible way are challenging to develop and have received considerable interest. Here, we present a printable hybrid material that can withstand numerous writing-erasing cycles. This material is based on a poly(methyl methacrylate) host matrix embedding by copolymerization of a red NIR phosphorescent metal cluster and a blue green 3-oxindole emitter. Irradiation of the homogeneous and stable hybrid films changes the emission color from white to deep red because of the oxygen perturbed energy transfer from the organic dye to the metal cluster. Because of the low PMMA gas permeability, encrypted data lifetime can be tuned from minutes to days, can be self-erased, and be rewritten at will. This material represents a key stepping stone for anticounterfeiting, optoelectronic, data recording, and many other technologies.
\end{abstract}

Keywords: Functional Coatings, Luminescence, hybrid material, Stimuli-Responsive Materials, Polymeric Materials

\section{Introduction}

Stimuli responsive emissive materials have drawn an increasing attention for their potential in applications such sensors, lighting, optoelectronic, or information storage. They can react to one or several external stimuli, such as a chemical or vapor exposure, a mechanical or electrical stress, light irradiation, or thermal treatment.[1-5] Light is an easy to use external stimulus[6-13] and for this reason, luminescence that is a straightforward responsive signal, is a useful tool that can be integrated in responsive materials[14-16] for optoelectronic devices, data recording and storage, security and anti-counterfeiting, etc. Stability and reversibility of the material response are in many cases an important issue that needs to be carefully considered to target applications. Materials that can store data for a prescribed period of time are also needed for secure communications.[17-21] These materials, when rewritable, could help to lower the ecological impact of the traditional paper industry from the production to the recycling.[22] Although security inks that allow thermal rewriting of invisible printed images have already been described,[20,23,24] dual emissive materials answering to the same light stimulus for writing and reading are unprecedented. Such straightforward encryption-decryption process would be highly convenient and cost-effective for the end-users. Moreover, dual emissive materials can deliver efficiently a tailored emission that depends on the concentration and ratio of dyes. As demonstrated herein, they provide a better contrast between irradiated and non-irradiated area and respond more efficiently to a light stimulus compared to a single emitting system. The challenge in a dual emitter design lies on the finding of emitters robust toward photobleaching. Fluorescent pseudoindoxyl derivatives containing the 3 -oxindole core structure have received increasing interest in biological imaging. [25,26] Recently, some authors developed a straighforward two-step approach to access various multi-allylated 3-oxindoles arising from an allylationoxidation sequence generating water as the only side product of the reactions.[27] Hence, we chose a 3-oxindole organic derivative (Oxi),[27] as a blue-green emitter, and an octahedral molybdenum cluster compound (Mo6) to deliver a red NIR emission. Octahedral transition metal cluster compounds of general formula $\mathrm{A}_{n} \mathrm{M}_{6} \mathrm{X}_{8}{ }_{8} \mathrm{~L}^{\mathrm{a}}{ }_{6}(\mathrm{~A}=$ alkali cation, $\mathrm{M}=$ transition metal; $X^{\mathrm{i}}$ : inner ligand; $\mathrm{L}^{\mathrm{a}}$ : apical ligand, see Figure 1), are welldefined aggregates of metal atoms linked by metal-metal bonds.[28] These molecular phosphorescent inorganic dyes can show quantum yield reaching unity,[29] possess an excellent photostability,[30] a very large Stokes shift,[31] and, unlike quantum dots, such Stokes shift is achieved without the need of complex structure engineering.[32] They are obtained mostly by solid state chemistry techniques, starting from cheap and earth abundant elements, contain neither cadmium nor lead, and can be integrated in various host matrices for large-scale and publicdedicated devices once their ceramic-like behavior is circumvent.[33] This lack of process ability remained a major drawback, despite their outstanding functionalities, until 1995, when Golden et al. integrated them successfully in nanocomposites via solution chemistry.[34] Ever since, octahedral transition metal clusters represent an entire research field within nanoscience and were incorporated in functional materials by several strategies such as direct integration,[35] apical ligand exchange,[36] cationic metathesis[37] or host-guest complexation.[38,39] Mo6 clusters excited state reacts efficiently with oxygen.[40,41] This ability allows their use in $\mathrm{O}_{2}$ sensor devices[42,43] or as theranostic tool in photodynamic therapy.[29,44,45] Poly(methyl methacrylate ) (PMMA), with a triplet energy of $3.1 \mathrm{eV},[46]$ is a suitable wide band gap host material that does not disturb infrared or visible triplet states emitters. As all polymers, PMMA has a high degree of rigidity compared to other host matrices, which makes it a material of choice to observe luminescence and, more specifically, phosphorescence from organic emitters.[47] Here, we present a nanocomposite able to switch reversibly its emission color from white to red, depending on the strength of its UV-exposure. This color switch is governed by the dynamic quenching of an energy transfer between both emitters governed by the local oxygen concentration. We show that data are only readable under UV light and are gradually self-erased because of the low polymer host gas permeability. The erasure times are controlled by exposure to UV light during the writing processes and can also be thermally accelerated.

\section{Materials and methods}

All chemicals were purchased from Aldrich or Alfa Aesar. Methyl methacrylate (MMA) monomer was distilled before use. Azobisisobutyronitrile (AIBN) was purified by recrystallization before being used as a radical polymerization initiator. The 
polymerizable $\left(\mathrm{C}_{29} \mathrm{H}_{58} \mathrm{NO}_{2}{ }^{+}\right)_{2}\left[\mathrm{Mo} 6 \mathrm{I}_{8}\left(\mathrm{C}_{2} \mathrm{~F}_{5} \mathrm{OCO}\right)_{6}\right]^{2-} \quad$ cluster (Mo6)[30] and Oxi,[27] were synthetized by reported procedures with conform analytical data. NMR experiments in solution were realized at $298 \mathrm{~K}$ in deuterated acetone with a Bruker Ascend 500 $\mathrm{MHz}$ NMR spectrometer. All peaks were referenced to the methyl signals of TMS at $\delta=0 \mathrm{ppm}$. DSC measurements were realized at $10 \mathrm{~K} \cdot \mathrm{min}^{-1}$ with a TA25 DSC apparatus. IR spectra were obtained with a Perkin Elmer IR spectrometer.

UV-vis absorption measurements were performed on a Varian Cary 5000 UV-Vis-NIR spectrophotometer. The absolute quantum yields in the solid state and in solution were measured with a C9920-03 Hamamatsu system. Temperature-dependent emission spectra, time-dependent emission spectra at $-180^{\circ} \mathrm{C}$, and fatigue studies were recorded using a home-made set-up containing a light excitation source (Nikon $\mathrm{Hg}$ Intensilight with optical filters allowing an excitation ranging from 380-420 nm bandwidth) coupled to an optical microscope mounted with a CCD detector Ocean optics QE65000 and a Linkam "liquid crystal pro system" hotstage LTS420. Movies and time-gated emission spectra at $77 \mathrm{~K}$ were realized with a $5 \mathrm{~mW} 405 \mathrm{~nm}$ laser diode and an Ocean optics QE65000 CCD detector. Lifetime measurements and TRPL mapping at $296 \mathrm{~K}$ were realized using a picosecond laser diode (Jobin Yvon deltadiode, $375 \mathrm{~nm}$ ) and a Hamamatsu C10910-25 streak camera mounted with a slow single sweep unit. Signals were integrated on the entire emission decay. Fits were calculated using origin software and the goodness of fit judge by the reduced $\chi^{2}$ value and residual plot shape. $\mathrm{O}_{2}\left({ }^{1} \Delta_{\mathrm{g}}\right)$ measurements were realized with a Hamamatsu H12397-75 NIR-PMT unit mounted on a IHR3 spectrometer. Excitation of thin films was realized with a $375 \mathrm{~nm}$ laser diode (Jobin Yvon deltadiode). Temperature-dependent lifetime measurements were realized using a Edinburgh FLS960 spectrometer equipped with a R928P Hamamatsu photodetector, a microflash and nanoflash lamps. Detection was realized on a 10 $\mathrm{nm}$ bandwidth centered on the emission maximum of the desired emitter. Temperature was controlled using an Oxford Instrument Optistat cryostat.

Irradiations for the encryption were realized through home-made masks using a 4w UV 2A lamp with an excitation wavelength of $368 \mathrm{~nm}$. Writing was realized with a $5 \mathrm{~mW} 405 \mathrm{~nm}$ laser pointer.

\section{Synthesis.}

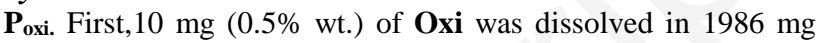
(99.3\% wt.) of distilled MMA. After the addition of $4 \mathrm{mg}(0.2 \%$ wt.) of AIBN, the solution was sonicated for $10 \mathrm{~min}$ to obtain a homogenous mixture, degassed 5 min under $\mathrm{Ar}$, and placed in an oven at $65^{\circ} \mathrm{C}$ for 17 hours to obtain a transparent greenish polymer pellet. ${ }^{1} \mathrm{H}-\mathrm{NMR}\left(500 \mathrm{MHz},\left(\mathrm{CD}_{3}\right)_{2} \mathrm{CO}\right): 3.63$ (s, 3H, $\left.\mathrm{CH}_{3}-\mathrm{O}\right), 2.03-1.44\left(\mathrm{~m}, 2 \mathrm{H},-\mathrm{CH}_{2}-\right), 1.43-0.70\left(\mathrm{~m}, 3 \mathrm{H}, \alpha-\mathrm{CH}_{3}-\right)$. IR: $\bar{v}=1143 \mathrm{~cm}^{-1}, \delta_{\mathrm{C}-\mathrm{O}-\mathrm{C}}, \mathrm{F} ; \bar{v}=1240 \mathrm{~cm}^{-1}, v_{\mathrm{C}-\mathrm{O}-\mathrm{C}}, \mathrm{m} ; \bar{v}=1633$

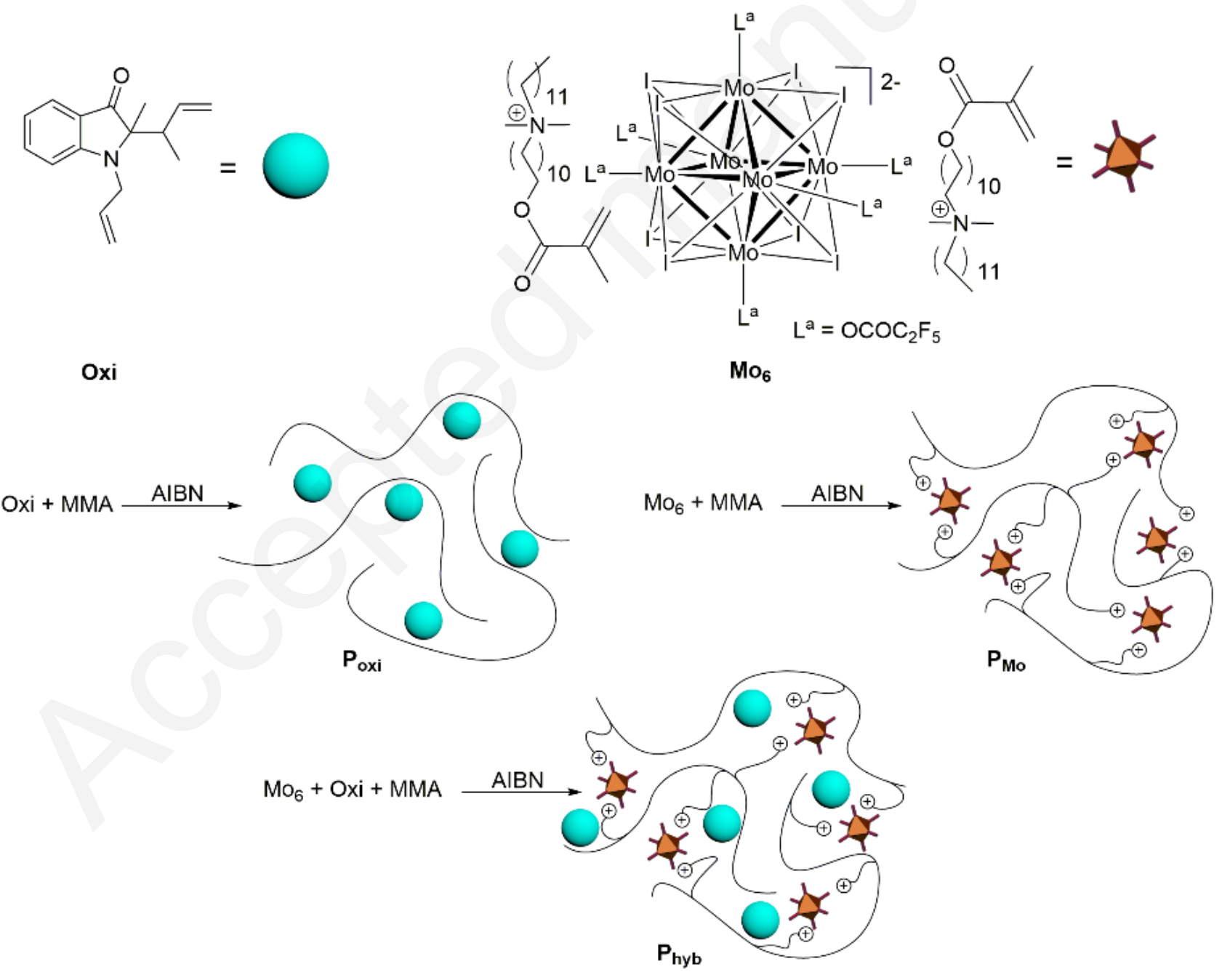

Figure 1. Schematic representation of organic and inorganic precursors used in this studies and copolymerization reactions. 
$\mathrm{cm}^{-1}, v_{\mathrm{Car}-\mathrm{Car}}, \mathrm{F} ; \bar{v}=1722 \mathrm{~cm}^{-1}, v_{\mathrm{C}=\mathrm{O}}, \mathrm{F} ; \bar{v}=2951 \mathrm{~cm}^{-1}, v_{\mathrm{CH} 3-\mathrm{sp} 3}, \mathrm{f}$. $\mathrm{T}_{\mathrm{g}}=70.2^{\circ} \mathrm{C}$.

Phyb. The same procedure as that for $\mathbf{P}_{\text {oxi }}$ was followed with 10 $\mathrm{mg}(0.5 \% \mathrm{wt}$ ) of $\mathbf{O x i}, 40 \mathrm{mg}(2 \% \mathrm{wt})$ of Mo6 and $1946 \mathrm{mg}$ (97.3\% wt.) of distilled MMA. ${ }^{1} \mathrm{H}-\mathrm{RMN}\left(500 \mathrm{MHz},\left(\mathrm{CD}_{3}\right)_{2} \mathrm{CO}\right)$ : 3.63 (s, 3H, $\left.\mathrm{CH}_{3}-\mathrm{O}\right), 2.03-1.44\left(\mathrm{~m}, 2 \mathrm{H},-\mathrm{CH}_{2}-\right), 1.43-0.70(\mathrm{~m}, 3 \mathrm{H}$, $\left.\alpha-\mathrm{CH}_{3}-\right) .{ }^{19} \mathrm{~F}-\mathrm{RMN}\left(470 \mathrm{MHz},\left(\mathrm{CD}_{3}\right)_{2} \mathrm{CO}\right):-82.98$ (t, 3F), -120.63 (m, 2F). IR: $\bar{v}=1143 \mathrm{~cm}^{-1}, \delta \mathrm{C}-\mathrm{O}-\mathrm{C}, \mathrm{F} ; \bar{v}=1240 \mathrm{~cm}^{-1}, v_{\mathrm{C}-\mathrm{O}-\mathrm{C}, \mathrm{m} ; \bar{v}}$ $=1633 \mathrm{~cm}^{-1}, v_{\mathrm{Car}-\mathrm{Car}}, \mathrm{F} ; \bar{v}=1722 \mathrm{~cm}^{-1}, v_{\mathrm{C}=0}, \mathrm{~F} ; \bar{v}=2951 \mathrm{~cm}^{-1}$, $v_{\mathrm{CH} 3-\mathrm{sp} 3}$, f. $\mathrm{T}_{\mathrm{g}}=70.2^{\circ} \mathrm{C}$.

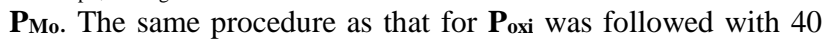
mg (2\%wt.) of Mo6 and $1956 \mathrm{mg}$ (97.8\%wt) of distilled MMA. A transparent orange polymer pellet was obtained. ${ }^{1} \mathrm{H}-\mathrm{RMN}(500$ $\left.\mathrm{MHz},\left(\mathrm{CD}_{3}\right)_{2} \mathrm{CO}\right): 3.62$ (s, 3H, $\left.\mathrm{CH}_{3}-\mathrm{O}\right), 2.03-1.40\left(\mathrm{~m}, 2 \mathrm{H},-\mathrm{CH}_{2}-\right.$ ), 1.40-0.69 (m, 3H, $\left.\alpha-\mathrm{CH}_{3}-\right) .{ }^{19} \mathrm{~F}-\mathrm{RMN}\left(470 \mathrm{MHz},\left(\mathrm{CD}_{3}\right)_{2} \mathrm{CO}\right)$ : 82.98 (t, 3F), -120.63 (m, 2F). IR: $\bar{v}=1240 \mathrm{~cm}^{-1}, v_{\mathrm{C}-\mathrm{O}-\mathrm{C}}, \mathrm{m} ; \bar{v}=$ $1143 \mathrm{~cm}^{-1}, \delta_{\mathrm{C}-\mathrm{O}-\mathrm{C}}, \mathrm{F} ; \bar{v}=1722 \mathrm{~cm}^{-1}, v_{\mathrm{C}=\mathrm{O}}, \mathrm{F} ; \bar{v}=2951 \mathrm{~cm}^{-1}, v_{\mathrm{CH} 3-}$ sp3, f. $\mathrm{T}_{\mathrm{g}}=97.1^{\circ} \mathrm{C}$.

Thin films were obtained by slow evaporation of dichloromethane solution (10 ml) containing $\mathbf{P}_{\text {oxi }}, \mathbf{P}_{\text {hyb }}$ or $\mathbf{P}_{\mathbf{M o}}$.

\section{Results and discussion \\ 3.1. Synthesis and characterization.}

As depicted in Figure 1, three copolymers were synthesized by radical polymerization: one containing the blue green 3 -oxindole organic fluorophore[27] (Oxi) at $0.5 \mathrm{wt} \%\left(\mathbf{P}_{\text {oxi }}\right)$, another one containing the red NIR emitting molybdenum cluster[30] (Mo6) at $2 \mathrm{wt} \%$ ( $\mathbf{P}_{\mathbf{M o}}$ ) and a third one containing the same amount of both luminophores $\left(\mathbf{P}_{\text {hyb }}\right)$. Polymers were characterized by NMR, IR, and DSC (see ESI for synthetical procedures and Figure S1S7). Concentrations were chosen a posteriori taking into account the Förster radius calculated for the two emitters once embedded in the host matrix $\left(\mathrm{R}_{0}=4.48 \mathrm{~nm}\right.$, see ESI for the Förster radius calculation and Figure S8).[48] Despite the presence of two unsaturations on Oxi, it is well known that unactivated double bonds display low reactivity under RP (radical polymerization) and CRP (controlled radical polymerization) conditions.[49] Therefore, Oxi is rather more homogeneously dispersed than copolymerized like many other dyes integrated in PMMA.[50-52] In the contrary, the Mo6 cluster compound bearing a methacrylate function on its organic counter cations is copolymerized which prevents inorganic-organic phase segregation.[37] Glass transition temperatures of $\mathbf{P}_{\text {oxi }}$ and $\mathbf{P}_{\text {hyb }}\left(70.2^{\circ} \mathrm{C}\right)$ is lower than usual $\mathrm{T}_{\mathrm{g}}$ observed for PMMA (around $100^{\circ} \mathrm{C}$ ) which can be imparted to a plasticizing effect induced by Oxi. The $\mathrm{T}_{\mathrm{g}}$ determined for $\mathbf{P}_{\mathbf{M o}}\left(97.1^{\circ} \mathrm{C}\right)$ is in good accordance with already reported results.[30,37] Homogeneous and transparent thin films were obtained by drop casting concentrated polymer solutions into Petri dishes (see pictures in Figure 2). They show intense luminescence upon UV-Vis irradiation $\left(\lambda_{\text {exc }}=360-480 \mathrm{~nm}\right)$. Transmission measurements reveal that the absorption cut off increases from $300 \mathrm{~nm}$ for $\mathbf{P}_{\mathbf{M o}}$ to $350 \mathrm{~nm}$ for $\mathbf{P}_{\mathbf{o x i}}$ and $450 \mathrm{~nm}$ for $\mathbf{P}_{\text {hyb }}$ (see ESI Figure $\mathbf{S 8}$ for transmission spectra).

\subsection{Emission properties.}

Figure 2a-d presents the emission vs excitation maps of copolymer films. Poxi map shows that the best excitation wavelength to observe the blue green emission is located between 400 and $420 \mathrm{~nm}$. Absolute Quantum Yield (AQY) values of 0.4 and 0.36 were determined in aerated and deaerated Oxi dichloromethane solution respectively. A similar value was calculated once embedded in PMMA (Table 1). Hence, the AQY does not appear, at first sight, to be sensitive to the atmosphere composition (vide infra). As expected, the introduction Mo6 in the PMMA matrix via the electrostatic approach leads to a perfectly homogeneous red emitting polymer $\mathbf{P M o}_{\text {Mo. [30] The Mor }}$ cluster emits in the red NIR area with an emission maximum located around $680 \mathrm{~nm}$ at $296 \mathrm{~K}$. The optimal excitation wavelength lies between 360 and $420 \mathrm{~nm}$. Bubbling $\mathrm{N}_{2}$ in a PMo containing dichloromethane solution increases its AQY from 0.02 to 0.46 and its emission lifetime from 5 to $211 \mu \mathrm{s}$ (see ESI Table S1 and Figures S10-S26, for kinetic data, related emission decay maps and integrated emission decay profiles). This known phenomenon originates from the dynamic quenching of the Mo6 excited triplet state by triplet oxygen $\mathrm{O}_{2}\left({ }^{3} \sum_{\mathrm{g}}{ }^{-}\right)$thus producing the emissive $\mathrm{O}_{2}\left({ }^{1} \Delta_{\mathrm{g}}\right)$. [41,53] As this process is a physical one, it does not generate any fatigue from the emitter and is perfectly reversible. In the solid state, the average emission lifetime deduced from $\mathbf{P}_{\text {Mo }}$ emission decay profile passes from $52.2 \mu$ s in air to $222 \mu \mathrm{s}$ in vacuum, while saturating the sample atmosphere with $\mathrm{N}_{2}$ leads to an increase of its AQY from 0.1 to 0.37 . The same trend is observed for $\mathbf{P}_{\text {hyb }}$ either as a thin film or in dichloromethane solution: bubbling $\mathrm{N}_{2}$ in a $\mathbf{P}_{\text {hyb }}$ solution increases the average cluster lifetime from 1.4 to $153 \mu$ s, while in the solid state, it increases from 31.6 to $282 \mu$ s when passing from air to vacuum at $300 \mathrm{~K}$.

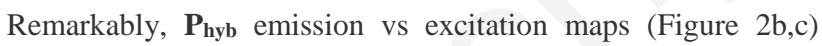
highlight a decrease in the organic emitter emission band along with an increase in the intensity of the cluster emission under inert atmosphere, which might indicate an effective energy transfer between both luminophores. The same phenomenon is observed when $\mathbf{P}_{\text {hyb }}$ is continuously irradiated as depicted in Figure 2e. To confirm that these changes are caused by $\mathrm{O}_{2}$, we investigated the emission abilities of all hybrids in the NIR area (see ESI Figures S27-S30). When several $\mathrm{O}_{2}\left({ }^{1} \Delta_{\mathrm{g}}\right)$ emission spectra were recorded successively for a $\mathbf{P}_{\text {hyb }}$ thin film, we observed a decrease of the $\mathrm{O}_{2}\left({ }^{1} \Delta \mathrm{g}\right)$ emission signal together with an increase in the cluster emission band. Performing the same experiment with $\mathbf{P}_{\text {oxi }}$ leads to a very weak emission of $\mathrm{O}_{2}\left({ }^{1} \Delta_{\mathrm{g}}\right)$ during the first acquisition, thus evidencing an emitting triplet state that could barely be detected by measurements under inert atmosphere at $300 \mathrm{~K}$ (vide infra). Yet, this specific behaviour implies that the host matrix is not permeable enough to allow a fast diffusion of external $\mathrm{O}_{2}$ in the surrounding of the emitting cluster or Oxi ligand. This phenomenon represents the fundamental principle of our imprinting process presented in Figure 2. Increasing the irradiation time has also a strong influence on the AQY value of $\mathbf{P}_{\text {hyb }}$ that passes from 0.05 before irradiation to 0.1 after being irradiated for $10 \mathrm{~min}$ under a basic $365 \mathrm{~nm}$ UV lamp in air atmosphere.

\subsection{Data encryption-decryption and erasing.}

Polymer films emissions were then monitored under an extended UV exposure. During irradiation, a slow decrease of $\mathbf{P}_{\mathbf{o x i}}$ emission band intensity is observed together with a slight red shift. For $\mathbf{P}_{\mathbf{h y b}}$, the Oxi emission band centred at $475 \mathrm{~nm}$ diminishes slightly while the cluster emission band centred around $680 \mathrm{~nm}$ increases strongly. Figure 2e presents normalized spectra for irradiated and non-irradiated $\mathbf{P}$ hyb area. The writing is realized using a $5 \mathrm{~mW}$ $405 \mathrm{~nm}$ laser beam (see ESI, video S1) while imprinting is performed irradiating continuously samples through a mask with a 4 W UV-2A during 300s. As depicted in the 1931 CIE coordinates diagram (Figure 2f), the perceived colour is highly sensitive to $\mathrm{O}_{2}$ concentration. In air atmosphere, irradiating $\mathbf{P}_{\text {hyb }}$ from 380 up to $430 \mathrm{~nm}$ leads to a white emission with chromaticity coordinates values in the $1931 \mathrm{CIE}$ colour diagram comprised between $0.296<x<0.318$ and $0.290<y<0.35$, while a red colour is obtained in a $\mathrm{N}_{2}$ saturated atmosphere. Note that a deep red emission with $\mathrm{x}>0.68$ is always observed for $\mathrm{P}_{\mathrm{Mo}}$ regardless of the excitation wavelength. PMMA is known to have a low $\mathrm{O}_{2}$ permeability.[54,55] Irradiating doped polymers leads to a decrease in the local $\mathrm{O}_{2}$ concentration due to the $\mathrm{O}_{2}\left({ }^{3} \Sigma_{\mathrm{g}}{ }^{-}\right)$ consumption by excited triplet states. As a result, these triplet states emit more efficiently, which modify significantly the perceived emission color for $\mathbf{P}_{\text {hyb. }}$. 
Table 1. Photophysical data (average lifetimes and absolute quantum yield) recorded on thin films.

\begin{tabular}{|c|c|c|c|c|c|c|c|c|c|c|}
\hline & \multicolumn{8}{|c|}{ average lifetimes } & \multicolumn{2}{|c|}{$\operatorname{AQY}\left(\lambda_{\text {exc }}=365 \mathrm{~nm}\right)$} \\
\hline & \multicolumn{5}{|c|}{$300 \mathrm{~K}$} & \multirow{2}{*}{\multicolumn{3}{|c|}{$\begin{array}{l}77 \mathrm{~K} \\
\text { Vacuum }\end{array}$}} & \multirow{3}{*}{ Air } & \multirow{3}{*}{$\mathrm{N}_{2}$} \\
\hline & Air & & Vacul & & & & & & & \\
\hline & $\begin{array}{l}\mathrm{F}_{\text {oxi }}{ }^{a} \\
{[\mathrm{~ns}]}\end{array}$ & $\begin{array}{l}\mathrm{Ph}_{\mathrm{Mo}{ }^{\mathrm{b}}} \\
{[\mu \mathrm{s}]}\end{array}$ & $\begin{array}{l}F_{o x i}{ }^{a} \\
{[n s]}\end{array}$ & $\begin{array}{l}\mathrm{Ph}_{\text {oxi }}{ }^{\mathrm{a}} \\
{[\mathrm{ms}]}\end{array}$ & $\begin{array}{l}\mathrm{Ph}_{\mathrm{Mo}^{\mathrm{b}}} \\
{[\mu \mathrm{s}]}\end{array}$ & $\begin{array}{l}F_{\text {oxi }}{ }^{a} \\
{[n s]}\end{array}$ & $\begin{array}{l}\mathrm{Ph}{ }_{\mathrm{oxi}}{ }^{\mathrm{a}} \\
{[\mathrm{ms}]}\end{array}$ & $\begin{array}{l}\mathrm{Ph}_{\mathrm{Mo}}{ }^{\mathrm{b}} \\
{[\mu \mathrm{s}]}\end{array}$ & & \\
\hline$P_{\text {hyb }}$ & 5.9 & 31.6 & 14.4 & 6.3 & 282 & 18.7 & 400 & 486 & 0.13 & 0.38 \\
\hline$P_{\text {oxi }}$ & 5.9 & - & 15.4 & 7.9 & - & 17.2 & 533 & - & 0.35 & 0.35 \\
\hline $\mathrm{P}_{\mathrm{Mo}}$ & - & 52.2 & - & - & 222 & - & - & 295 & 0.10 & 0.37 \\
\hline
\end{tabular}

Integration area $=450-548 \mathrm{~nm} ;{ }^{b}$ integration area $=612-748 \mathrm{~nm} ;$ average lifetime is calculated as $\tau=\left(\sum \mathrm{aii}_{\mathrm{i}}{ }^{2}\right) /\left(\sum \mathrm{ai}_{\mathrm{i}} \tau_{\mathrm{i}}\right) ; \mathrm{F}:$ fluorescence; $\mathrm{Ph}$ : phosphorescence.

a)

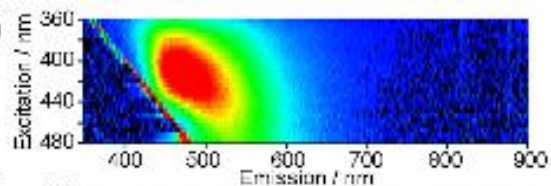

b)

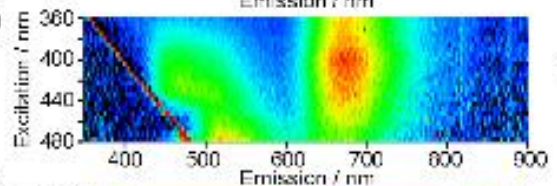

c)

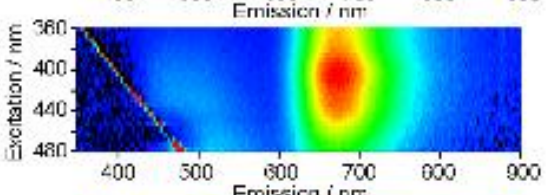

d)
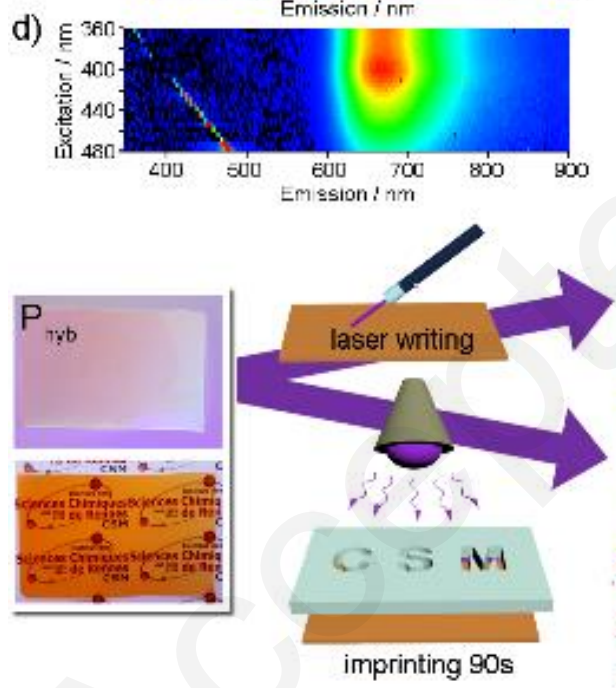

imprinting $90 s$

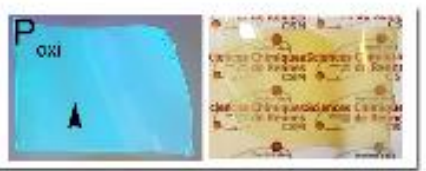

e)
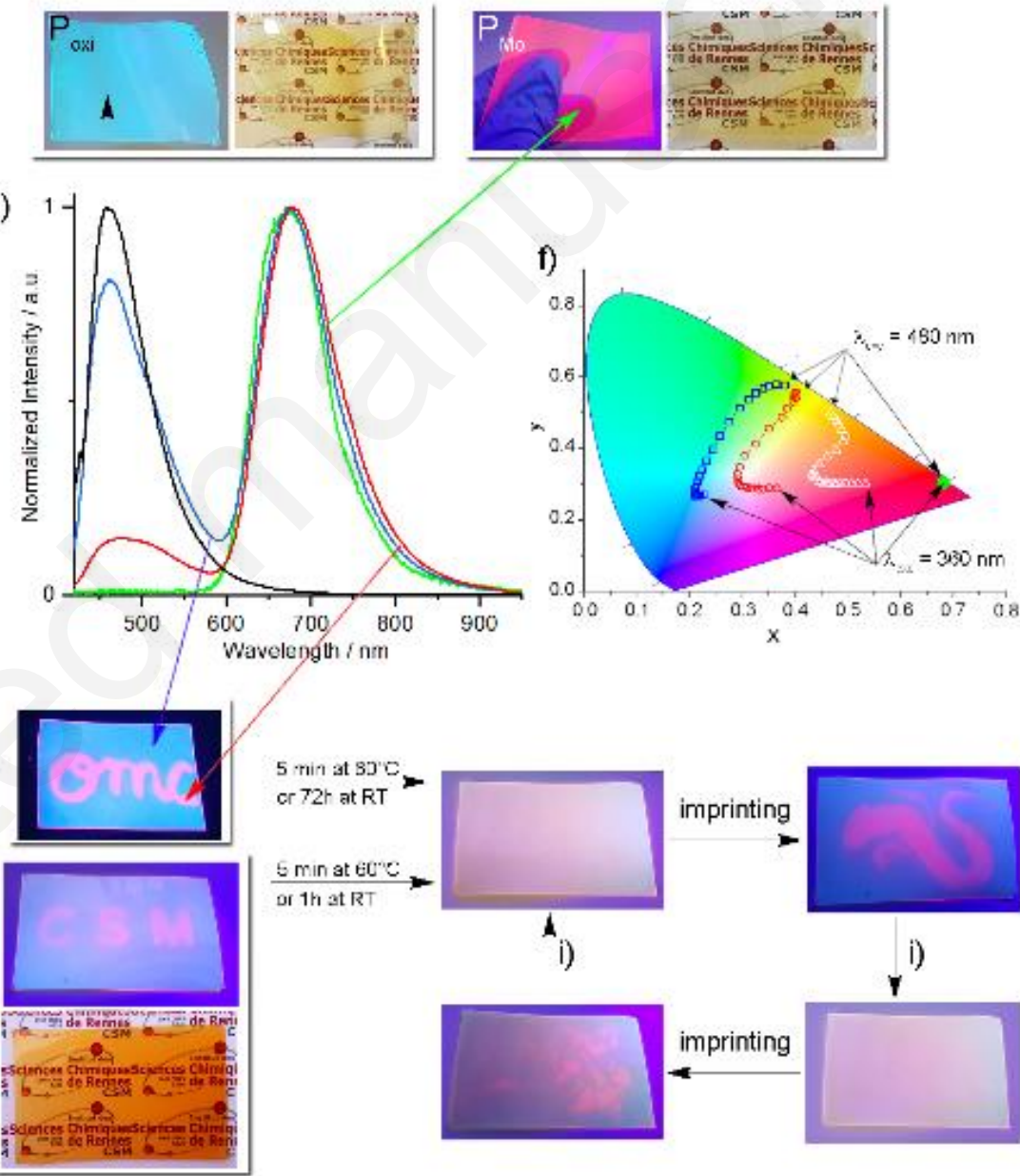

imprinting

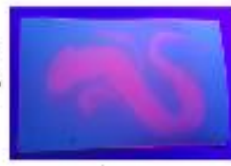

i)

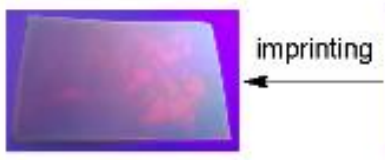

Figure 2. Emission vs excitation maps of a) $\mathbf{P}_{\mathbf{x x i}}$ and b) $\mathbf{P}_{\mathbf{H y b}}$ in an air atmosphere, c) $\mathbf{P}_{\mathbf{H y b}}$ in a $\mathrm{N}_{2}$ atmosphere; d) $\mathbf{P}_{\mathbf{M o}}$ in an air atmosphere (intensity increases from dark blue to red); e) Emission spectra at $25^{\circ} \mathrm{C}$ observed under $405 \mathrm{~nm}$ excitation (laser diode $5 \mathrm{~mW}$ ) for $\mathbf{P}_{\text {oxi }}$ (black), $\mathbf{P}_{\text {Hyb }}$ (irradiation time : $10 \mathrm{~ms}$ (blue), $10 \mathrm{~s}$ (red), $\mathbf{P}_{\mathbf{M o}}$ (green), inset: pictures of $\mathbf{P}_{\text {oxi }}$ and $\mathbf{P}_{\mathbf{M o}}$ thin films under UV (365 nm) and sunlight; f) 1931 CIE coordinates diagram of $\mathbf{P}_{\mathbf{o x i}}$ (blue square) and $\mathbf{P}_{\mathbf{H y b}}$ in air atmosphere (red circle) or under $\mathrm{N}_{2}$ atmosphere (white triangles), $\mathbf{P}_{\text {Mo }}$ (green diamond), excitation varies from 360 up to $480 \mathrm{~nm}$ by $5 \mathrm{~nm}$ steps; Schematic presentation of writing ( $5 \mathrm{~mW}$, 405 $\mathrm{nm}$ laser pointer) and imprinting process using UV-light ( $\boldsymbol{\lambda}_{\mathrm{exc}}=365 \mathrm{~nm}, \mathrm{UV}-2 \mathrm{~A} 4 \mathrm{w}$ ); photographs of $\mathbf{P}_{\mathbf{H y b}}$ under UV light (365 nm) and solar light; i) the erasing step is performed either by heating the sample up to $60^{\circ} \mathrm{C}$ during 5 minutes or by waiting at $20^{\circ} \mathrm{C}$ for an amount of time depending on the irradiation power used during the imprinting step. 
Because the oxygen consumption rate is related to the excited state generation, 300 seconds are needed to stabilize the cluster emission with a 4W UV-2A lamp while the equilibrium is reached in $7 \mathrm{~s}$ using a $405 \mathrm{~nm} 5 \mathrm{~mW}$ laser beam (vide infra).

Hence, the imprinted motif appears red with surrounding white, while the film stays transparent and unmarked under solar light (Figure 2). This process is fully reversible as imprinted motives self-erase gently due to the slow diffusion of $\mathrm{O}_{2}$ in the copolymer. Clearly, their appearance and full disappearance depends on several factors: the power and time of UV exposure as well as the film thickness (around $350 \mu \mathrm{m}$ in our case according to SEM measurements, see ESI Figure S31). We observed that for $90 \mathrm{~s}$ of irradiation with a UV-2A $4 \mathrm{~W}$ tube, the drawing could disappear after $1 \mathrm{~h}$, while an irradiation of $5 \mathrm{~min}$ led to a persistence of several days (see ESI Figure S32). Data erasing can be accelerated by a gentle heating at $60^{\circ} \mathrm{C}$ during 5 min that increases the copolymer chains mobility and therefore also increases its $\mathrm{O}_{2}$ permeability. It can also be performed efficiently in a laboratory using vacuum/air cycles.

\subsection{Evidencing energy transfers between the two luminophores.}

$\mathrm{O}_{2}\left({ }^{1} \Delta_{\mathrm{g}}\right)$ emission studies performed on $\mathbf{P}_{\mathbf{o x i}}$, clearly evidenced that Oxi possesses a triplet excited state. However, AQY values calculated either in aerated or deaerated Oxi solutions $(\mathrm{AQY} \approx$ $0.4)$ are very similar, and the same trend is observed for $\mathbf{P}_{\text {oxi in }}$ air or $\mathrm{N}_{2}$ saturated atmosphere $(\mathrm{AQY}=0.06)$ at $296 \mathrm{~K}$. Hence, temperature-assisted deactivation of this triplet state is dominant at room temperature. This point is well illustrated by temperature dependent emission studies. For $\mathrm{P}_{\text {oxi }}$, we observed on cooling a clear red shift of the emission maximum due to the enhancement of the emission signal located around $520 \mathrm{~nm}$ (see ESI Figure S33-S34 for temperature dependent emission spectra). For $\mathbf{P}_{\mathbf{M o}}$, passing from $300 \mathrm{~K}$ to $77 \mathrm{~K}$ induces, as expected, a shift of the Mo6 cluster emission maximum from 680 to $650 \mathrm{~nm}$, a narrowing and an increase in the emission signal.[56,57] Both phenomenon are observed in $\mathbf{P}_{\text {hyb. }}$.

Definitely, the Oxi triplet excited state emission is best observed by time-gated emission performed at $77 \mathrm{~K}$ when $\mathbf{P}_{\text {hyb }}$ and $\mathbf{P}_{\text {oxi }}$ are

a)

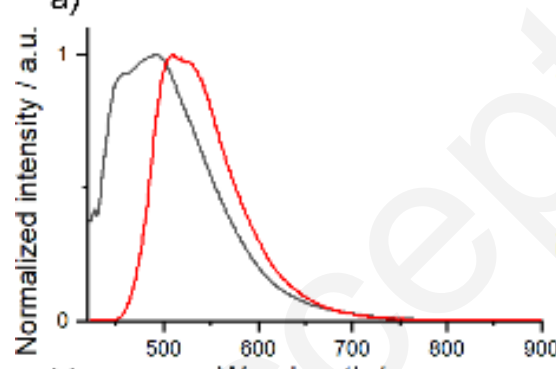

b)

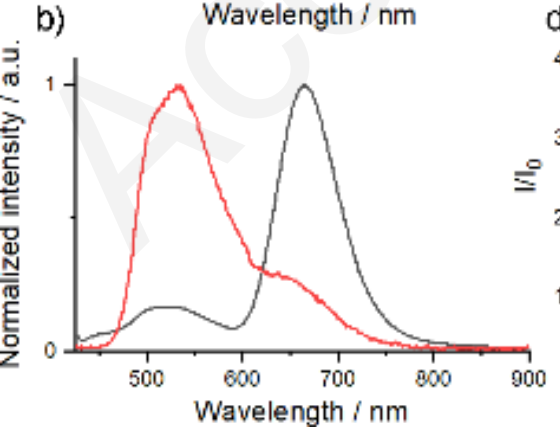

c)

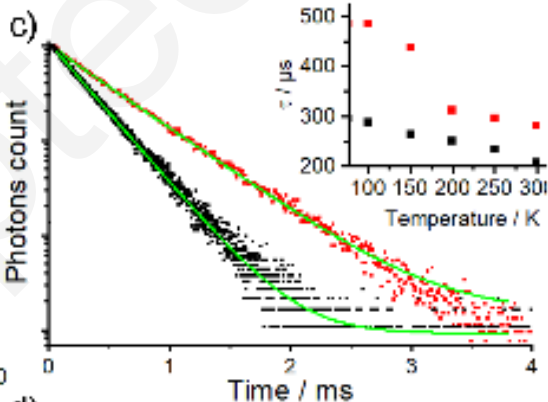

d)

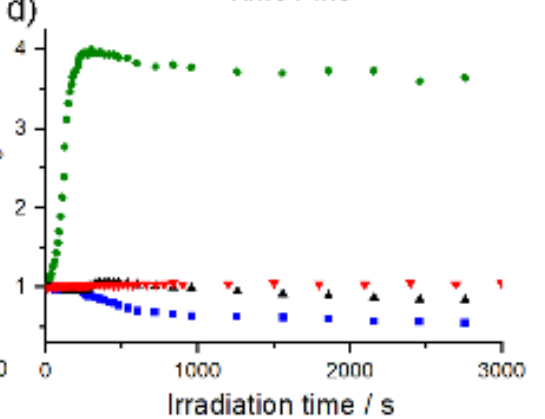

dipped in liquid nitrogen and irradiated at $405 \mathrm{~nm}$. Figure 3a and 3b present emission spectra recorded during irradiation (in black) and $10 \mathrm{~ms}$ after the irradiation is switched off (in red) for $\mathbf{P}_{\mathbf{o x i}}$ and $\mathbf{P}_{\text {hyb }}$ respectively. They clearly evidence a partial energy transfer between the Oxi $\mathrm{T}_{1}$ state and the Mor cluster anion. While during irradiation, the bluish emission band combines the fluorescence and phosphorescence of Oxi, only a green phosphorescence occurs $10 \mathrm{~ms}$ after excitation (see ESI video S2). As presented in Table 1, the average lifetime of this long-lived emission passes from $7.9 \mathrm{~ms}$ at $296 \mathrm{~K}$ to $533 \mathrm{~ms}$ at $77 \mathrm{~K}$ for $\mathbf{P}_{\text {oxi }}$ (see ESI Table S2 and Figures S35-S36 for temperature-dependent transient emission data). For $\mathbf{P}_{\text {hyb, the }}$ Oxi phosphorescence lifetime is significantly shorter (from $6.3 \mathrm{~ms}$ at $296 \mathrm{~K}$ to $400 \mathrm{~ms}$ at $77 \mathrm{~K}$ ) which evidences the resonance part of the all energy transfer occuring between Oxi and Mo6. This transfer is confirmed by the appearance of the cluster anion emission band together with the Oxi phosphorescence one after irradiation (Figure 3b, red curve and ESI Figure S37-S38).

These energy transfers have also a strong impact on the Mo6 cluster emission lifetime whose value increases by $165 \%$ in the presence of Oxi at $77 \mathrm{~K}$ (Figure 3c). The phenomenon is still observable at $300 \mathrm{~K}$ with an increase from $222 \mu \mathrm{s}$ ( $\left.\mathrm{P}_{\mathrm{Mo}}\right)$ to $277 \mu \mathrm{s}$ (Phyb). According to temperature-dependent transient measurements, these energy transfers become more efficient below $200 \mathrm{~K}$ (see inset Figure 3c).

Despite the previous experimental and theoretical studies dealing with the rationalization of Mo6 cluster emission properties,[56,58-60] it remains difficult to explain accurately which Mo6 energy levels or sublevels are involved in these energy transfers, as not only the Mo6 ground state but also Mo6 excited states could be involved. Moreover, the global energy transfer can not be assessed to only one type of transfer as it is a combination of resonance and radiative transfer. Yet, the simplified Jablonsky diagrams presented in Figure 3e summarize photophysical measurement results. They highlight the major role played by oxygen in the all emission process. In air, the Oxi triplet emission is quenched due to non-radiative deactivation and to its reaction with $\mathrm{O}_{2}$ leading to $\mathrm{O}_{2}{ }^{1} \Delta_{\mathrm{g}}$ emission. Although efficient, the quenching of Mo6 emission by $\mathrm{O}_{2}\left({ }^{3} \Sigma_{\mathrm{g}}{ }^{-}\right)$is not complete and Mo6

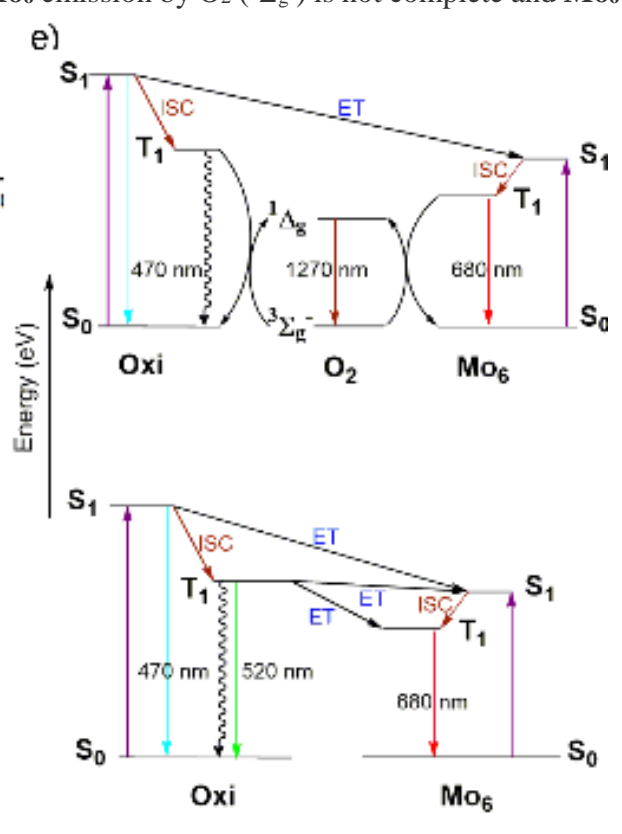

Figure 3. Time-gated normalized emission spectra observed at 77K (black line: during irradiation, red line : $10 \mathrm{~ms}$ after irradiation) for a) $\mathbf{P}_{\text {oxi and b) }} \mathbf{P}_{\text {hyb }}$; c) Mor emission decay profiles observed at $77 \mathrm{~K}$ in $\mathbf{P}_{\mathbf{M o}}$ (black) and $\mathbf{P}_{\text {hyb }}$ (red), inset: temperature dependence of $\mathbf{M o 6}$ average lifetime values in $\mathbf{P}_{\text {Mo }}$ (black) and $\mathbf{P}_{\text {hyb }}$ (red); d) Follow up of emission intensity under constant UV-2A irradiation at 296 K (green disk: $\mathbf{P}_{\text {hyb }}$ emission at $680 \mathrm{~nm}$; blue square : $\mathbf{P}_{\text {hyb }}$ emission at $480 \mathrm{~nm}$; black triangle: $\mathbf{P}_{\text {oxi }}$ emission at $480 \mathrm{~nm}$; red reverse triangle : $\mathbf{P}_{\mathbf{M o}}$ emission at $680 \mathrm{~nm}$ ); e) Jablonsky energy diagram of $\mathbf{P h y b}$ with (top) and without (bottom) oxygen. 
emission is observed. In the lack of $\mathrm{O}_{2}$, Oxi transfers part of its energy to Mo6 via singlet-singlet, triplet-singlet, and triplet-triplet energy transfer.

\subsection{Behavior under continuous irradiation and decryption fatigue studies.}

Polymer films were irradiated continuously on a microscope equiped with a UV-2A source and their emission was monitored for one hour (Figure 3d and ESI Figure S39. S40). It is clear that their emission behaviour, up to the full consumption of $\mathrm{O}_{2}$ embedded in the host matrix, will depend on several factors: mainly the power and the duration of irradiation, as well as the sample thickness that governs the $\mathrm{O}_{2}$ concentration profile within the material. During the first 300 seconds, a large increase by $400 \%$ of the Mor intensity signal associated to a slow decrease by $40 \%$ of the $S_{1}$ Oxi emission signal is observed for $\mathbf{P}_{\text {hyb. This increase can not }}$ only be assessed to the local decrease of $\mathrm{O}_{2}$ concentration, as it is barely observed for $\mathbf{P}_{\text {Mo. It originates also from the }}$ energy transfers between both emitters. From 300 up to 500 s, Mo6 and Oxi moities enter in a stationary regime as their emission tend to stabilize afterwards. For $\mathbf{P}_{\text {oxi }}$, a little increase of the Oxi emission band is also observed during the first $300 \mathrm{~s}$ and the emission stabilizes after a slight decrease.

As expected, the $\mathbf{P}_{\text {hyb }}$ emission envelope evolves much faster under a more powerful irradiation with a $405 \mathrm{~nm} 5 \mathrm{~mW}$ Laser. During this experiment, the stationary regime is reached after $7 \mathrm{~s}$ for the cluster emission band $\left(\lambda_{\text {exc }}=405\right.$ $\mathrm{nm}$, see ESI Figure S41). In these irradiation conditions, $\mathbf{P}_{\text {Mo }}$ emission intensity increases by $200 \%$ and stabilizes after 200 s (see ESI Figure S42).

As UV light can be used to write, read, and delete encrypted data, we studied the ability of our material to support a low to moderate UV exposure. These experiments were performed to get an idea about the time available to read encrypted data under irradiation without degrading them. Figure 4 summarizes the experiments realized and main results. Imprinted films were irradiated for several seconds (10, 30 or $45 \mathrm{~s}$ with a UV-2A irradiation) and then allowed to stand for $10 \mathrm{~min}$. The emission signal was recorded before and after irradiation. This cycle was repeated at least 10 times (see ESI, Figure S43). First, irradiating $\mathbf{P}_{\text {hyb }}$ during only $10 \mathrm{~s}$ does not modify its envelope emission signal, i.e.: the emission intensity maxima of Oxi and Mo6 are kept at the same level. Hence, a short irradiation does not modify the encrypted informations that can be read without damages. Increasing the irradiation time leads to an increase of Mos cluster emission intensity. However, for $30 \mathrm{~s}$ of irradiation, the Oxi signal is still more intense than the one of Mo6. The contrast between imprinted and non imprinted area is lowered. Increasing the irradiation time to $45 \mathrm{~s}$ leads, after the second cycle, to a large increase of the cluster

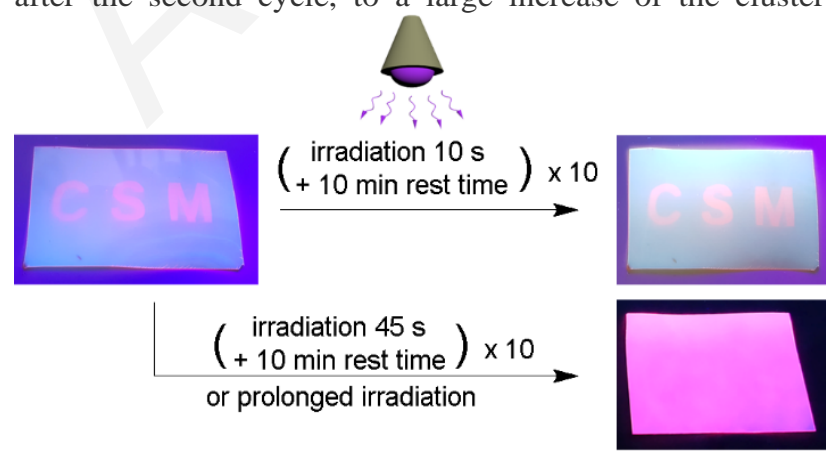

emission and a decrease of the Oxi emission band. Hence, at this power of irradiation, the material is entering in the imprinting process, and encrypted data can be erased after 10 cycles or by an extended irradiation.

\section{Conclusions}

In summary, we have designed a flexible hybrid 3D nanomaterial gathering stable organic and inorganic emitters in a PMMA host matrix. The obtained emissive thin film reacts efficiently to UV light irradiation by changing its emission color from white to deep red. This ability was used to print information directly on the polymer film. The nanocomposite emission color changes are controlled by the dynamic quenching of an energy transfer governed by the local oxygen concentration, that drops down when triplet oxygen $\mathrm{O}_{2}\left({ }^{3} \Sigma_{\mathrm{g}}\right)$ reacts with the excited triplet states of emitters to generate the reactive $\mathrm{O}_{2}\left({ }^{1} \Delta_{\mathrm{g}}\right)$. Data are only readable under UV light and are gradually self-erased because of the low polymer host gas permeability. The erasure times are easily controlled by exposure to UV light during the writing processes and can also be thermally accelerated. Temperatureand time-dependent photophysical studies evidenced energy transfers between the organic blue green emitter $S_{1}$ and $T_{1}$ excited states and the phosphorescent metal cluster $S_{1}$ and $T_{1}$ excited states. Taking into consideration the versatility of the synthesis from the organic and inorganic point of view, the wide choice of host matrices governing the gas permeability of the hybrid and therefore the reactivity of the color changes; taking also in consideration the cost effectiveness and the ease of the data encryption-decryption process, we anticipate that these materials will be promising candidates for applications in optical data recording, sensors or anti-counterfeiting devices.

\section{Supporting Information}

\section{Declaration of interest}

S. K., Y. M., M. A and M. A. C. are inventors on a patent application related to this work filed by the Université de Rennes1, CNRS, ENSCR, INSA Rennes (EP19305523.3 filed on 23 April 2019. All other authors declare no conflict of interest.

\section{Contributions}

S. K. and N. F. L. R. performed synthesis, analysis of copolymers and emission measurements; S. P. and S. C. worked on the cluster precursor synthesis; M. A. C. initiated the cluster in PMMA integration, performed DSC and IR analysis; H. A.-K. and G. T. investigated temperature dependent transient emission properties. S. D. and M. A. synthesized the Oxi derivatives; M. A. and Y. M. initiated the idea of the studies; Y. M. supervised the studies, performed emission measurements and wrote the manuscript. All authors participated in the proofreading and correction of the manuscript.

\section{Acknowledgements}

S.K. thanks ANR Renoir for financial support. L. Joanny and F. Gouttefangeas from CMEBA -UMS 2001 ScanMat are acknowledged for SEM measurements.

\section{References}

[1] Sagara, Y., and Kato, T., Mechanically induced luminescence changes in molecular assemblies, Nature Chem. (2009) 1 (8), 605-610. https://doi.org/10.1038/nchem.411

[2] Yamane, S., Tanabe, K., Sagara, Y., Kato, T., Stimuliresponsive photoluminescent liquid crystals, Top. Curr. Chem. (2012) 318 (Liquid Crystals), 395-406. https://doi.org/10.1007/128_2011_275

Figure 4. Decryption fatigue studies under a UV2A lamp irradiation 
[3] Ma, X., and Tian, H., Stimuli-Responsive Supramolecular Polymers in Aqueous Solution, Acc. Chem. Res. (2014) 47 (7), 19711981. https://doi.org/10.1021/ar500033n

[4] Tsang, M.-K., Bai, G., Hao, J., Stimuli responsive upconversion luminescence nanomaterials and films for various applications, Chem. Soc. Rev. (2015) 44 (6), 1585-1607.

https://doi.org/10.1039/C4CS00171K

[5] Cariati, E., Lucenti, E., Botta, C., Giovanella, U., Marinotto,

D., Righetto, S., Cu(I) hybrid inorganic-organic materials with intriguing stimuli responsive and optoelectronic properties, Coord. Chem. Rev. (2016) 306 (Part_2), 566-614

https://doi.org/10.1016/j.ccr.2015.03.004

[6] Bouas-Laurent, H., and Durr, H., Organic photochromism, Pure Appl. Chem. (2001) 73 (4), 639-665.

https://doi.org/10.1351/pac200173040639

[7] Liu, N., Chen, Z., Dunphy, D. R., Jiang, Y.-B., Assink, R. A. Brinker, C. J., Photoresponsive nanocomposite formed by self-assembly of an azobenzene-modified silane, Angew. Chem., Int. Ed. (2003) 42

(15), 1731-1734. https://doi.org/10.1002/anie.200250189

[8] Moriyama, M., Mizoshita, N., Yokota, T., Kishimoto, K. Kato, T., Photoresponsive anisotropic soft solids: Liquid-crystalline physical gels based on a chiral photochromic gelator, Adv. Mater. (2003) 15 (16), 1335-1338. https://doi.org/10.1002/adma.200305056

[9] Kobatake, S., Takami, S., Muto, H., Ishikawa, T., Irie, M., Rapid and reversible shape changes of molecular crystals on photoirradiation, Nature (2007) 446 (7137), 778-781.

https://doi.org/10.1038/nature05669

[10] Yagai, S., and Kitamura, A., Recent advances in photoresponsive supramolecular self-assemblies, Chem. Soc. Rev. (2008) 37 (8), 1520-1529. https://doi.org/10.1039/b703092b

[11] Habault, D., Zhang, H., Zhao, Y., Light-triggered self-healing and shape-memory polymers, Chem. Soc. Rev. (2013) 42 (17), 7244 7256. https://doi.org/10.1039/c3cs35489j

[12] Swaminathan, S., Garcia-Amoros, J., Fraix, A., Kandoth, N., Sortino, S., Raymo, F. M., Photoresponsive polymer nanocarriers with multifunctional cargo, Chem. Soc. Rev. (2014) 43 (12), 4167-4178. https://doi.org/10.1039/C3CS60324E

[13] Molard, Y., Bassani, D. M., Desvergne, J.-P., Horton, P. N., Hursthouse, M. B., Tucker, J. H. R., Photorelease of an organic molecule in solution: Light-triggered blockage of a hydrogen-bonding receptor site, Angew. Chem., Int. Ed. (2005) 44 (7), 1072-1075, S1072/1071-S1072/1073. https://doi.org/10.1002/anie.200461946 [14] Yu, X., Chen, H., Shi, X., Albouy, P.-A., Guo, J., Hu, J., Li, M.-H., Liquid crystal gelators with photo-responsive and AIE properties, Mater. Chem. Front. (2018) 2 (12), 2245-2253.

https://doi.org/10.1039/C8QM00340H

[15] Zhang, Y., Zhou, S., Chong, K. C., Wang, S., Liu, B., Nearinfrared light-induced shape memory, self-healable and anti-bacterial elastomers prepared by incorporation of a diketopyrrolopyrrole-based conjugated polymer, Mater. Chem. Front. (2019) 3 (5), 836-841. https://doi.org/10.1039/C9QM00104B

[16] Alam, P., Leung, N. L. C., Cheng, Y., Zhang, H., Liu, J., Wu, W., Kwok, R. T. K., Lam, J. W. Y., Sung, H. H. Y., Williams, I. D., Tang, B. Z., Spontaneous and Fast Molecular Motion at Room Temperature in the Solid State, Angew. Chem. Int. Ed. (2019) 58 (14), 4536-4540. https://doi.org/10.1002/anie.201813554

[17] Kishimura, A., Yamashita, T., Yamaguchi, K., Aida, T., Rewritable phosphorescent paper by the control of competing kinetic and thermodynamic self-assembling events, Nature Mater. (2005) 4, 546. https://doi.org/10.1038/nmat1401

https://www.nature.com/articles/nmat1401\#supplementary-information [18] Zhang, C., Wang, B., Li, W., Huang, S., Kong, L., Li, Z., Li, L., Conversion of invisible metal-organic frameworks to luminescent perovskite nanocrystals for confidential information encryption and decryption, Nature Commun. (2017) 8 (1), 1138. https://doi.org/10.1038/s41467-017-01248-2

[19] Horiuchi, N., Self-erasing images, Nature Photon. (2009) 3 (11), 613. https://doi.org/10.1038/nphoton.2009.195

[20] Klajn, R., Wesson, P. J., Bishop, K. J. M., Grzybowski, B. A., Writing Self-Erasing Images using Metastable Nanoparticle "Inks", Angew. Chem., Int. Ed. (2009) 48 (38), 7035-7039, S7035/7031S7035/7017, 7017. https://doi.org/10.1002/anie.200901119 [21] Lin, J., Wan, S., Liu, W., Lu, W., Photo-writing self-erasable phosphorescent images using poly(N-vinyl-2-pyrrolidone) as a photochemically deoxygenating matrix, Chem. Commun. (2019) 55 (30), 4299-4302. https://doi.org/10.1039/C9CC01388A
[22] Müller, V., Hungerland, T., Baljozovic, M., Jung, T., Spencer, N. D., Eghlidi, H., Payamyar, P., Schlüter, A. D., Ink-Free Reversible Optical Writing in Monolayers by Polymerization of a Trifunctional Monomer: Toward Rewritable "Molecular Paper", $A d v$. Mater. (2017) 29 (27), 1701220

https://doi.org/10.1002/adma.201701220

[23] Khazi, M. I., Jeong, W., Kim, J.-M., Functional Materials and Systems for Rewritable Paper, Adv. Mater. (2018) 30 (15), 1705310. https://doi.org/10.1002/adma.201705310

[24] Panda, T., Maiti, D. K., Panda, M. K., Inkless Writing and Self-Erasing Security Feature of (Z)-1,2-Diarylacrylonitrile-Based Materials: A Confidential Data Communication, ACS Appl. Mater. Interfaces (2018) 10 (34), 29100-29106.

https://doi.org/10.1021/acsami.8b08279

[25] Lee, J. H., So, J.-H., Jeon, J. H., Choi, E. B., Lee, Y.-R.,

Chang, Y.-T., Kim, C.-H., Bae, M. A., Ahn, J. H., Synthesis of a new

fluorescent small molecule probe and its use for in vivolipid imaging,

Chem. Commun. (2011) 47 (26), 7500-7502.

https://doi.org/10.1039/C1CC11253H

[26] Chen, H., Shang, H., Liu, Y., Guo, R., Lin, W., Development of a Unique Class of Spiro-Type Two-Photon Functional Fluorescent Dyes and Their Applications for Sensing and Bioimaging, Adv. Funct. Mater. (2016) 26 (44), 8128-8136.

https://doi.org/10.1002/adfm.201603495

[27] Lauwick, H., Sun, Y., Akdas-Kilig, H., Dérien, S., Achard, M., Access to 3-Oxindoles from Allylic Alcohols and Indoles, Chem. Eur. J. (2018) 24 (31), 7964-7969.

https://doi.org/10.1002/chem.201800348

[28] Cotton, F. A., Metal Atom Clusters in Oxide Systems, Inorg Chem. (1964) 3 (9), 1217-1220. https://doi.org/10.1021/ic50019a003

[29] Kirakci, K., Kubat, P., Dusek, M., Fejfarova, K., Sicha, V., Mosinger, J., Lang, K., A Highly Luminescent Hexanuclear Molybdenum Cluster - A Promising Candidate toward Photoactive Materials, Eur. J. Inorg. Chem. (2012) (19), 3107-3111.

https://doi.org/10.1002/ejic.201200402

[30] Amela-Cortes, M., Molard, Y., Paofai, S., Desert, A., Duvail, J.-L., Naumov, N. G., Cordier, S., Versatility of the ionic assembling method to design highly luminescent PMMA nanocomposites containing [M6Qi8La6]n- octahedral nano-building blocks, Dalton Trans. (2016) 45 (1), 237-245. https://doi.org/10.1039/C5DT03734D [31] Zhao, Y., and Lunt, R. R., Transparent Luminescent Solar Concentrators for Large-Area Solar Windows Enabled by Massive Stokes-Shift Nanocluster Phosphors, Adv. Energy Mater. (2013) 3 (9), 1143-1148. https://doi.org/10.1002/aenm.201300173

[32] Zhou, Y., Zhao, H., Ma, D., Rosei, F., Harnessing the properties of colloidal quantum dots in luminescent solar concentrators, Chem. Soc. Rev. (2018) 47 (15), 5866-5890.

https://doi.org/10.1039/C7CS00701A

[33] Cordier, S., Grasset, F., Molard, Y., Amela-Cortes, M., Boukherroub, R., Ravaine, S., Mortier, M., Ohashi, N., Saito, N., Haneda, H., Inorganic Molybdenum Octahedral Nanosized Cluster Units, Versatile Functional Building Block for Nanoarchitectonics, $J$. Inorg. Organomet. Polym. Mater. (2015) 25 (2), 189-204. https://doi.org/10.1007/s10904-014-0112-2

[34] Golden, J. H., Deng, H. B., Disalvo, F. J., Frechet, J. M. J., Thompson, P. M., Monodisperse Metal-Clusters 10-Angstroms in Diameter in a Polymeric Host - the Monomer-as-Solvent Approach, Science (1995) 268 (5216), 1463-1466.

https://doi.org/10.1126/science.268.5216.1463

[35] Robin, M., Kuai, W., Amela-Cortes, M., Cordier, S., Molard, Y., Mohammed-Brahim, T., Jacques, E., Harnois, M., Epoxy Based Ink as Versatile Material for Inkjet-Printed Devices, ACS Appl. Mater. Interfaces (2015) 7 (39), 21975-21984. https://doi.org/10.1021/acsami.5b06678

[36] Molard, Y., Labbe, C., Cardin, J., Cordier, S., Sensitization of Er3+ Infra red Photoluminescence embedded in an Hybrid OrganicInorganic Copolymer containing Octahedral Molybdenum Clusters., Adv. Funct. Mater. (2013) 23 (38), 4821-4825. https://doi.org/10.1002/adfm.201300417

[37] Amela-Cortes, M., Garreau, A., Cordier, S., Faulques, E., Duvail, J.-L., Molard, Y., Deep red luminescent hybrid copolymer materials with high transition metal cluster content, J. Mater. Chem. C (2014) 2 (8), 1545-1552. https://doi.org/10.1039/c3tc31309c

[38] Molard, Y., Clustomesogens: Liquid Crystalline Hybrid Nanomaterials Containing Functional Metal Nanoclusters, Acc. Chem. 
Res. (2016) 49 (8), 1514-1523.

https://doi.org/10.1021/acs.accounts.6b00236

[39] Robin, M., Dumait, N., Amela-Cortes, M., Roiland, C., Harnois, M., Jacques, E., Folliot, H., Molard, Y., Direct Integration of Red-NIR Emissive Ceramic-like AnM6Xi8Xa6 Metal Cluster Salts in Organic Copolymers Using Supramolecular Interactions, Chem. Eur. J. (2018) 24 (19), 4825-4829. https://doi.org/10.1002/chem.201800860 [40] Maverick, A. W., Najdzionek, J. S., MacKenzie, D., Nocera, D. G., Gray, H. B., Spectroscopic, electrochemical, and photochemical properties of molybdenum(II) and tungsten(II) halide clusters, J. Am. Chem. Soc. (1983) 105 (7), 1878-1882.

https://doi.org/10.1021/ja00345a034

[41] Jackson, J. A., Turro, C., Newsham, M. D., Nocera, D. G., Oxygen quenching of electronically excited hexanuclear molybdenum and tungsten halide clusters, J. Phys. Chem. (1990) 94 (11), 4500-4507. https://doi.org/10.1021/j100374a029

[42] Ghosh, R. N., Baker, G. L., Ruud, C., Nocera, D. G., Fiberoptic oxygen sensor using molybdenum chloride cluster luminescence, Appl. Phys. Lett. (1999) 75 (19), 2885-2887.

https://doi.org/10.1063/1.125180

[43] Amela-Cortes, M., Paofai, S., Cordier, S., Folliot, H., Molard, Y., Tuned Red NIR phosphorescence of polyurethane hybrid composites embedding metallic nanoclusters for oxygen sensing, Chem. Commun.

(2015) 51, 8177-8180. https://doi.org/10.1039/C5CC01867F

[44] Vorotnikova, N. A., Efremova, O. A., Tsygankova, A. R., Brylev, K. A., Edeleva, M. V., Kurskaya, O. G., Sutherland, A. J.,

Shestopalov, A. M., Mironov, Y. V., Shestopalov, M. A.,

Characterization and cytotoxicity studies of thiol-modified polystyrene microbeads doped with [\{Mo6X8\}(NO3)6]2- $(\mathrm{X}=\mathrm{Cl}, \mathrm{Br}, \mathrm{I})$, Polym. Adv. Technol. (2016) 27 (7), 922-928. https://doi.org/10.1002/pat.3749 [45] Brandhonneur, N., Hatahet, T., Amela-Cortes, M., Molard, Y., Cordier, S., Dollo, G., Molybdenum cluster loaded PLGA nanoparticles: An innovative theranostic approach for the treatment of ovarian cancer, Eur. J. Pharm. Biopharm. (2018) 125, 95-105. https://doi.org/https://doi.org/10.1016/j.ejpb.2018.01.007 [46] Avdeenko, A. A., Dobrovolskaya, T. L., Kultchitsky, V. A., Naboikin, Y. V., Pakulov, S. N., Temperature dependence of luminescence decay time of benzyl, J. Lumin. (1976) 11 (5), 331-337. https://doi.org/https://doi.org/10.1016/0022-2313(76)90017-X [47] Oster, G., Geacintov, N., Khan, A. U., Luminescence in plastics, Nature (1962) 196, 1089-1090.

https://doi.org/10.1038/1961089a0

[48] Wu, P. G., and Brand, L., Resonance Energy Transfer: Methods and Applications, Anal. Biochem. (1994) 218 (1), 1-13. https://doi.org/https://doi.org/10.1006/abio.1994.1134

[49] Matsumoto, A., Asai, S., Aota, H., Free-radical crosslinking polymerization of unsymmetrical divinyl compounds, 1 Gelation in the polymerization of allyl methacrylate, Macromol. Chem. Phys. (2000) 201 (18), 2735-2741. https://doi.org/10.1002/15213935(20001201)201:18<2735::AID-MACP2735>3.0.CO;2-F

Data availability

The raw data required to reproduce these findings cannot be shared at this time due to technical or time limitations.
[50] An, Z., Zheng, C., Tao, Y., Chen, R., Shi, H., Chen, T., Wang, Z., Li, H., Deng, R., Liu, X., Huang, W., Stabilizing triplet excited states for ultralong organic phosphorescence, Nature Mater (2015) 14 (7), 685-690. https://doi.org/10.1038/nmat4259 [51] Parafiniuk, K., Sznitko, L., Wawrzynczyk, D., Miniewicz, A., Mysliwiec, J., Enlargement of the organic solid-state DFB laser wavelength tuning range by the use of two complementary luminescent dyes doped into the host matrix, Phys. Chem. Chem. Phys. (2017) 19 (27), 18068-18075. https://doi.org/10.1039/C7CP02249B

[52] Costela, A., Garcia-Moreno, I., Barroso, J., Sastre, R., Laser performance of Coumarin 540A dye molecules in polymeric host media with different viscosities: From liquid solution to solid polymer matrix, J. Appl. Phys. (1998) 83 (2), 650-660. https://doi.org/10.1063/1.366755 [53] Jackson, J. A., Newsham, M. D., Worsham, C., Nocera, D. G., Efficient singlet oxygen generation from polymers derivatized with hexanuclear molybdenum clusters, Chem. Mater. (1996) 8 (2), 558-564. https://doi.org/10.1021/cm950443f

[54] MacCallum, J. R., and Rudkin, A. L., A novel technique for measuring TH diffusion constant of oxygen in polymer films, Eur. Polym. J. (1978) 14 (9), 655-656.

https://doi.org/https://doi.org/10.1016/0014-3057(78)90007-1

[55] Poulsen, L., and Ogilby, P. R., Oxygen Diffusion in Glassy Polymer Films: Effects of Other Gases and Changes in Pressure, $J$.

Phys. Chem. A (2000) 104 (12), 2573-2580.

https://doi.org/10.1021/jp993449r

[56] Akagi, S., Sakuda, E., Ito, A., Kitamura, N., Zero-MagneticField Splitting in the Excited Triplet States of Octahedral Hexanuclear Molybdenum(II) Clusters: [ Mo6X8\}(n-C3F7COO)6]2- $(\mathrm{X}=\mathrm{Cl}, \mathrm{Br}$, or I), J. Phys. Chem. A (2017) 121 (38), 7148-7156.

https://doi.org/10.1021/acs.jpca.7b06783

[57] Sokolov, M. N., Mihailov, M. A., Peresypkina, E. V., Brylev, K. A., Kitamura, N., Fedin, V. P., Highly luminescent complexes [Mo6X8(n-C3F7COO)6]2- (X = Cl, Br, I), Dalton Trans. (2011) 40 (24), 6375-6377. https://doi.org/10.1039/c1dt10376h

[58] Saito, Y., Tanaka, H. K., Sasaki, Y., Azumi, T., Temperature dependence of the luminescence lifetime of hexanuclear

molybdenum(II) chloride cluster. Identification of lower excited triplet sublevels, J. Phys. Chem. (1985) 89 (21), 4413-4415.

https://doi.org/10.1021/j100267a001

[59] Azumi, T., and Saito, Y., Electronic-Structures of the Lower Triplet Sublevels of Hexanuclear Molybdenum(Ii) Chloride Cluster, $J$.

Phys. Chem. (1988) 92 (7), 1715-1721. https://doi.org/10.1021/j100318a005

[60] Costuas, K., Garreau, A., Bulou, A., Fontaine, B., Cuny, J., Gautier, R., Mortier, M., Molard, Y., Duvail, J.-L., Faulques, E.,

Cordier, S., Combined theoretical and time-resolved photoluminescence investigations of [Mo6Bri8Bra6]2- metal cluster units: evidences of dual emission, Phys. Chem. Chem. Phys. (2015) 17, 28574-28585. https://doi.org/10.1039/C5CP03960F 